PONTIFÍCIA UNIVERSIDADE CATÓLICA DO RIO DE JANEIRO

Como transportar de maneira mais eficiente e barata água de coco natural da cidade de Petrolina (PE) para o Rio de Janeiro (RJ).

\title{
Ilann Fiszman Stemberg
}

Trabalho de Conclusão de Curso

CENTRO DE CIÊNCIAS SOCIAIS - CCS

DEPARTAMENTO dE ADMINISTRAÇÃO

Graduação em Administração de Empresas 


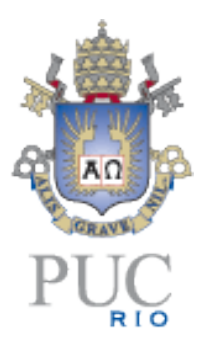

Ilann Fiszman Stemberg

Como transportar de maneira mais eficiente e barata água de coco natural da cidade de Petrolina (PE) para o Rio de Janeiro (RJ).

\section{Trabalho de Conclusão de Curso}

Trabalho de Conclusão de Curso, apresentado ao programa de graduação em Administração da PUC-Rio como requisito parcial para a obtenção do titulo de graduação em Administração.

Orientador (a): Isao Nishioka 


\title{
Resumo
}

Stemberg, Ilann. Determinando a maneira mais eficiente e barata água de coco natural da cidade de Petrolina (PE) para o Rio de Janeiro (RJ). Rio de Janeiro, 2016, 29 p. Trabalho de Conclusão de Curso - Departamento de Administração. Pontifícia Universidade Católica do Rio de Janeiro.

Segundo a revista Globo Rural o Brasil é o quarto país em produção do coco do mundo e o líder mundial considerando-se apenas a água de coco, tendo movimentado cerca de $\mathrm{R} \$ 450$ milhões de reais por ano. O Estado de Pernambuco é o sexto maior produtor do país, e Estado do Rio de Janeiro ainda é um dos maiores consumidores da água de coco. Dentro deste presente cenário o grande objetivo desse estudo é ver qual o meio de transporte mais viável para se levar água de coco envasada e sem conservantes da cidade de Petrolina (PE) para o Rio de Janeiro (RJ), através de uma pesquisa comparativa com os principais prestadores de serviços de transporte dos vários modais disponíveis.

\section{Palavras chaves}

Água de coco, Logística, transporte, Matriz de transporte.

\section{Abstract}

\author{
Stemberg, Ilann. Determining the most efficient and cheapest way to \\ transport natural coconut water from Petrolina (PE) to Rio de Janeiro (RJ). \\ Rio de Janeiro, 2016.2, 30 p. Trabalho de Conclusão de Curso - \\ Departamento de Administração. Pontifícia Universidade Católica do Rio de \\ Janeiro
}

According to Globo Rural Magazine, Brazil is the fourth country in the world in production of coconut and, considering only the coconut water, Brazil is in the leadership, reaching around $R \$ 450$ million per year. Pernambuco State is the sixth national coconut water producer, and Rio de Janeiro is one of the most expressive consumers. Within the present scenario, the purpose of this study is to determine the most efficient and inexpensive way to transport bottled coconut water without preservatives from Petrolina (PE) to Rio de Janeiro (RJ).

\section{Key-words}

Coconut water, Logistics, Transport, Transport Matrix. 


\section{Sumário}

1 O tema e o problema de estudo 1

1.1. Introdução ao tema e ao problema do estudo 1

1.2. Objetivo do estudo 2

1.3. Objetivos intermediários do estudo 3

1.4. Delimitação e foco do estudo 3

1.5. Justificativa e relevância do estudo 3

2. Revisão de literatura 4

2.1. Fatores de compra da água de coco. 4

2.1.1. Variável cultural 4

2.1.2. Variável social 5

2.1.3. Variável pessoal 5

2.1.4. Variável Psicológica 5

2.2. Estudo sobre a Matriz de transportes brasileira 6

2.2.1. Transporte Rodoviário $\quad 7$

2.2.2. Transporte Ferroviário 8

2.2.3. Transporte Hidroviário. 10

2.2.4. Transporte por dutos 11

2.2.5. Transporte aeroviário. 12

2.2.6. Serviços Integrados (Multimodais) 13

2.3. Características técnicas da água de coco. 13

2.3.1. Engarrafamento do produto 14

2.3.2. Embalagem 15

$\begin{array}{ll}\text { 2.3.3. Estocagem do produto } & 16\end{array}$

3 Métodos e procedimentos de coleta e de análise de dados do estudo. 18

3.1. Método de pesquisa utilizado. 18

3.2. Procedimento e coleta de dados. 18

3.3. Tratamento e análise dos dados coletados. 19

3.4. Limitações do método. 19 
4 Apresentação e análise dos resultados 20

4.1. Caracterização das empresas estudadas 20

4.1.1. Transporte por cabotagem 20

4.1.1.1. Aliança 20

4.1.1.2. Costa Brasil 21

4.1.1.3. MERCOSUL Line 21

4.1.1.4. Login Logística Intermodal 21

4.1.2. Transporte Aéreo 22

4.1.2.1. Kodex Express 22

4.1.2.2. CCA Express 22

4.1.2.3. AeroExpress 22

4.1.2.4. FlextimeCourier 23

4.1.3. Transporte rodoviário. 23

4.1.3.1. FlextimeCourier 23

4.1.3.2. Jamef 23

4.1.3.3. Custódia transportes 23

4.1.3.4. MG Frete 23

4.1.3.5. Arcelog 24

4.1.3.6. Frete de retorno. 24

4.2. Análise dos resultados 24

5 Conclusões e recomendações para novos estudos. 27

5.1. Sugestões e recomendações para novos estudos 27

6 Referências Bibliográficas $\quad 29$

$\begin{array}{ll}\text { Apêndice } & 31\end{array}$ 


\section{Lista de figuras}

Figura 1. Avaliação das condições das principais estradas do Brasil .................. 8

Figura 2. Mapa ferroviário Brasileiro .......................................................... 9

Figura 3. Principais Hidrovias do Brasil ...................................................... 11

Figura 4. Mapa dutoviário brasileiro ...................................................... 12

Figura 5. Modelo de copo do Fabricante ........................................................ 16

\section{Lista de tabelas}

Tabela 1 - Produção de coco, área plantada e produtividade do coqueiro dos principais estados brasileiros produtores .............................................. 2

Tabela 2. Matriz de transportes de carga do Brasil, seus respectivos custos por modal medidas em Toneladas por Quilômetro Útil (TKU) e seus respectivos custos (2012) e extensão de cada via. ................................................ 6

Tabela 3. Classificação e descrição de cada processo em que a água de coco pode ser comercializada......................................................................... 14

Tabela 4. Composição e requisitos para a venda de água de coco................... 14

Tabela 5. Preço desmembrado Aliança ........................................................... 21

Tabela 6. Preço desmembrado AeroExpress ............................................... 22 


\section{0 tema e o problema de estudo}

\subsection{Introdução ao tema e ao problema do estudo}

O Coco nucifera, nome científico do coco que os brasileiros estão acostumados a beber principalmente em seu litoral, atualmente é plantado em mais de 100 países, porém $80 \%$ de toda a sua produção é encontrada no Sudeste asiático, sendo a monocultura muito importante nutricionalmente e financeiramente para toda a região.

Conforme Noel (2008), 70\% do plantio mundial está concentrado na Índia, Filipinas e Indonésia, alcançando 48 milhões de toneladas em 2006. Nesses países o coco é um substituto da soja e as plantações recebem grande subsídio do governo para poderem se manter. É importante frisar que o mercado asiático comercializa em sua maioria o coco maduro, pois a sua carne é mais grossa e dura. Assim, ela é perfeita para a extração do óleo e para a fabricação do coco ralado.

Assim como nos países asiáticos, no Brasil "a cultura do coco assume posição importante como atividade geradora de emprego e renda, empregando mão de obra durante todo o ano" (FONTENELE, 2005 p. 3), todavia o coco Anão verde, que possui mais água, é o mais plantado nas terras tupiniquins "impulsionados principalmente pela inclusão de hábitos saudáveis no comportamento da população brasileira”. (MARTINS, C. R. et al., 2011 p. 14)

Segundo Martins o Brasil é o maior produtor de coco da América Latina e de 1990 para o ano de 2011 o país saltou da $10^{a}$ para a $4^{a}$ posição no ranking mundial com uma produção de 2,8 milhões de toneladas e, considerando apenas a água de coco, o Brasil é o maior produtor mundial. A cocoicultura no líder latino-americano de produção, como nos países do sudeste asiático, é de grande importância para a economia, principalmente no Nordeste, região de maior número de plantio nacional como podemos confirmar na tabela 1. 
Tabela 1 - Produção de coco, área plantada e produtividade do coqueiro dos principais estados brasileiros produtores.

\begin{tabular}{lccc}
\hline Estado & Produção (mil frutos) & Árvores plantadas (ha) & Produtividade (mil frutos/ha) \\
Bahia & 467080 & 79596 & 5,81 \\
Sergipe & 279203 & 42000 & 6,64 \\
Ceará & 259369 & 43448 & 5,97 \\
Pará & 248188 & 24663 & 10,10 \\
Espírito Santo & 157590 & 10625 & 14,83 \\
Pernambuco & 129822 & 14237 & 9,11 \\
Rio de Janeiro & 78419 & 4843 & 16,19
\end{tabular}

Fonte: IBGE - Produção Agrícola Municipal (2009).

Como demonstrado pela tabela 1, dos sete maiores produtores nacionais, quatro são do Nordeste, porém, em nível de produtividade, os Estados do Sudeste são superiores, seguido pelo Pará que, segundo a Revista Globo Rural, possui o maior coqueiral do mundo com um milhão de pés plantados, coqueiral este que pertence à Sococo, empresa líder do mercado de derivados de coco do Brasil.

Embora o Nordeste seja o maior produtor nacional, a Região Sudeste ainda é a maior consumidora nacional devido à sua maior concentração populacional e pela maior renda per capita. Assim, o grande desafio das fazendas e indústrias de coco natural no Nordeste é transportar no menor tempo possível e da maneira mais barata possível o produto de uma Região para a outra. Porém, dentro desta saga, alguns desafios devem ser cumpridos, por exemplo: A matriz de transportes no Brasil é cara e ineficiente, além disso, a água de coco possui validade de 30 dias quando resfriada e deve ser mantida em temperatura entre 0 e 5 graus para não congelar. Assim este trabalho procura responder a seguinte questão:

"Como transportar um produto produzido no Nordeste para o mercado consumidor do Sudeste de maneira segura e eficiente um produto que necessita um controle de temperatura entre 0 e 50 C?"

\subsection{Objetivo do estudo}

Considerando o grande potencial de crescimento da água de coco no mercado brasileiro, assim como a ineficiência da matriz de transportes nacional, o trabalho em questão tem como objetivo identificar a maneira mais barata e de monor tempo ao se transportar água de coco natural da maior região produtora nacional (Nordeste), para a maior consumidora (Sudeste), com maior enfoque nas cidades de Petrolina e Rio de Janeiro. 


\subsection{Objetivos intermediários do estudo}

Para alcançar o objetivo deste estudo, os seguintes objetivos intermediários deverão ser alcançados.

\footnotetext{
$\checkmark \quad$ Estudar a matriz de transportes nacional.

$\checkmark \quad$ Identificar a melhor maneira de conservação do coco resfriada.

$\checkmark \quad$ Estudar os momentos de maior consumo da água de coco.

$\checkmark \quad$ Encontrar meios alternativos de transportar o produto.

$\checkmark \quad$ Cuidados na embalagem para o transporte.

$\checkmark \quad$ Pesquisar preços de frete de diversas empresas presentes no mercado.

$\checkmark \quad$ Levantar processos de estocagem.
}

\subsection{Delimitação e foco do estudo}

O presente estudo tem como foco principal identificar as questões que envolvem o transporte de água de coco natural do estado de Pernambuco para o Rio de Janeiro. Mesmo sendo um produto com grande aceitação do público e em constante crescimento, poucos são os estudos presentes no meio acadêmico.

Como o coco possui diversos produtos derivados de sua fruta, é importante frisar que esse estudo é delimitado apenas à água de coco natural, que deve ser transportada refrigerada do Nordeste brasileiro para o Sudeste.

\subsection{Justificativa e relevância do estudo}

Por ser um mercado de grande expansão no mundo inteiro, e por ser a maneira de diversas famílias se sustentarem em várias cidades do Brasil e no mundo, o presente estudo pode ser justificado como um meio de os que estão presentes nesse mercado poderem compreendê-lo melhor e estudar as diferentes maneiras de transportar o Produto.

É notória a dificuldade em país continental como o Brasil de se praticar um frete competitivo e eficiente, podendo esse estudo ser esclarecedor para diversas empresas. 


\section{Revisão de literatura}

Neste capítulo são apresentados e abordados aspectos conceituais e alguns estudos relacionados ao tema, além de indagados temas que funcionarão como base para a análise realizada.

A presente seção está dividida em três partes, respectivamente, fator de compra de água de coco em seguida é apresentado um breve estudo sobre a matriz de transporte nacional, e, por último, algumas características técnicas do produto.

\subsection{Fatores de compra da água de coco.}

A onda de possuir uma vida saudável está cada vez maior, e por ser um produto positivo para a saúde, saboroso e um ótimo repositor de energia e eletrólitos, o consumo da água de coco vem crescendo ano a ano. De acordo com a reportagem da revista Globo Rural, o diretor da empresa Sococo, principal empresa do ramo no Brasil, Paulo Roberto Maya Gomes pretendia em 2012 aumentar a produção de trinta e sete milhões de litros para setenta milhões em 2016.

Existem quatro variáveis influentes na decisão de compra de um cliente, são elas: variável cultural, social, pessoal e psicológica.

\subsubsection{Variável cultural}

De acordo com Solomon (2002 p. 371) a variável cultural é "a acumulação de significados, rituais, normas e tradições compartilhadas entre os membros de uma organização". Conforme uma reportagem do Globo (2014), com a aproximação do verão e o aumento na temperatura, o preço e a demanda por água de coco cresce nas praias cariocas. Podemos assim relacionar que a cultura do carioca demonstra que, em dias de calor, maior quantidade de coco é demandada. Assim, é necessário que exista uma conexão da empresa com algum meio de previsão de temperatura, que auxiliará na estimativa de vendas. 


\subsubsection{Variável social}

Segundo Kotler e Keller (2006), grupos de referência influenciam no comportamento do individuo diretamente, estes podem ser primários, como família e amigos e secundários, como comunidades e associações, e estes geralmente não exigem interação contínua.

Como foi visto na variável cultural, a praia é um local de lazer cuja interação familiar e entre amigos existe. Isso significa que, em momentos como esses, a venda de água de coco pode ocorrer quando algum individuo do grupo adquire o produto. Como a comunidade atua na decisão de compra do consumidor, e o estudo é para a cidade do Rio de Janeiro, cidade praiana e com movimentos fitness, é provável que expor o produto para o consumidor em academias poderá ser visto como um fator positivo.

\subsubsection{Variável pessoal}

"As decisões do comprador também são influenciadas por características pessoais, como idade e estágio no ciclo de vida, ocupação, circunstâncias econômicas, personalidade, autoimagem, estilo de vida e valores (KOTLER; KELLER, 2006, p. 179)." A água de coco é um produto consumido por todas as faixas etárias e por todas as classes sociais. Esse produto é inclusive indicado para a hidratação durante algumas doenças e após exercício físico. Como o objetivo do produto é ser visto como algo saudável, este terá um enfoque em suas vendas em locais frequentados por pessoas compatíveis com esse estilo de vida.

\subsubsection{Variável Psicológica}

De acordo com Kotler e Keller (2006, p. 191): "um estilo de vida é o padrão de vida da pessoa expresso por atividades, interesses e opiniões". Isso faz com que as empresas tentem focar e criar produtos específicos para cada tipo de cliente, e em um mercado tão amplo como o de água de coco, a empresa precisa saber se posicionar no mercado e vender para o cliente exatamente o que ela é. No caso deste estudo, o objetivo é se posicionar como um produto saudável e natural, para clientes exigentes em relação ao sabor e aparência do produto. 


\subsection{Estudo sobre a Matriz de transportes brasileira}

O meio de transporte é o método utilizado para movimentar a mercadoria de um local para outro na cadeia de suprimento. Este pode ser feito por avião, caminhão, trem, navio e dutos. Os diferentes métodos se diferem na flexibilidade, custos, dimensões da entrega e velocidade do frete, afirmam Chopra e Meindl (2003).

Conforme Ballou (2006, p.191)," o transporte representa normalmente entre um e dois terços dos custos logísticos totais". Isso significa que estudar a matriz de transportes nacional, escolhendo o modal de transporte mais eficaz para o seu produto gera uma grande vantagem competitiva para a empresa, baixando o preço final do produto e, por se tratar de um produto perecível, mantém o produto por mais tempo disponível para vendas, visto que, após o vencimento de sua validade ele não pode mais ser consumido.

Como podemos ver na tabela 2, a matriz de transportes nacional é composta da seguinte maneira: $67 \%$ das mercadorias no Brasil são transportadas em rodovias, $18 \%$ por ferrovias, $11 \%$ em mares e rios, $3 \%$ por dutos e apenas $0,04 \%$ por vias aéreas. Podemos constatar que o principal meio de transporte de cargas nacional é o rodoviário.

Tabela 2. Matriz de transportes de carga do Brasil, seus respectivos custos por modal medidas em Toneladas por Quilômetro Útil (TKU) e seus respectivos custos e extensão de cada via.

\begin{tabular}{|c|c|c|c|}
\hline Modal & \%tku & US\$ / Mil TKU & US\$ / Mil TKU \\
\hline Rodoviário & $67 \%$ & US\$ 133 & US\$ 133 \\
\hline Ferroviário & $18 \%$ & US\$ 22 & US\$ 22 \\
\hline Aquaviário & $11 \%$ & US\$ 30 & US\$ 30 \\
\hline Dutoviário & $3 \%$ & US\$ 25 & US\$ 25 \\
\hline Aéreo & $0,04 \%$ & US\$ 1060 & US\$ 1060 \\
\hline
\end{tabular}

Fonte: Instituto de Logística e Supply Chain (Ilos), 2012, e World FactBook, Banco Mundial, 2014.

Além de estudar qual o melhor modal para o transporte da carga, Fleury et al. (2000, p. 269) afirmam que é essencial que haja entre todos os envolvidos uma parceria harmoniosa formada por um ambiente de confiança. Essa tarefa é complicada, visto que é bem provável que a cultura organizacional das partes seja distinta. Assim, conclui-se que a parceria deve ser vista pelo seu lado positivo, com o contratante sendo previsível em relação à sua demanda e a transportadora fornecendo uma área de coordenação eficiente e previsível. 


\subsubsection{Transporte Rodoviário}

O transporte rodoviário, único que possibilita o frete de porta a porta, é o ideal para pequenas rotas de produtos acabados ou semi-acabados. Ballou (1993) escreve que a distância média para caminhões deve ser de cerca de $480 \mathrm{~km}$ e de $274 \mathrm{~km}$ para veículos da própria frota. Além do serviço porta a porta, as outras duas grandes vantagens do transporte rodoviário são: a periodicidade e a liberdade do serviço e o fato de não ser necessário o descarregamento durante o trajeto porta a porta.

A Região Sudeste do Brasil é a maior exportadora nacional, seguida pela Região Sul, segundo a Comex do Brasil (2015). Isso pode gerar uma grande oportunidade com o a utilização do transporte rodoviário, visto que muitas vezes o modal volta vazio do Nordeste, fazendo com que o frete de retorno seja uma oportunidade de baratear o custo do transporte.

Mesmo não possuindo as condições mais favoráveis de acordo com a Pesquisa CNT de Rodovias (2016), em que $103.259 \mathrm{~km}$ de rodovias estaduais e federais foram avaliadas, com 58,2\% da amostra possuindo algum problema em relação ao seu estado, seja na sinalização, pavimentação ou geometria da via. A precariedade do asfalto nacional gera um aumento no custo de manutenção do veículo, eleva a quantidade do combustível a ser utilizado e é um causador de insegurança no motorista, fazendo um maior número de acidentes ocorrerem.

Como se vê na imagem na figura 1, existe uma grande integração de estradas entre as regiões pesquisadas, porém, é possível ver que a imagem ilustra a pesquisa realizada pela CNT, mostrando a grande quantidade de rodovias em estado regular, ruim ou péssimo no Brasil. Confirma também que o Sudeste é a região com as melhores estradas do país.

Fonte - CNT, 2007 
Figura 1. Avaliação das condições das principais estradas do Brasil

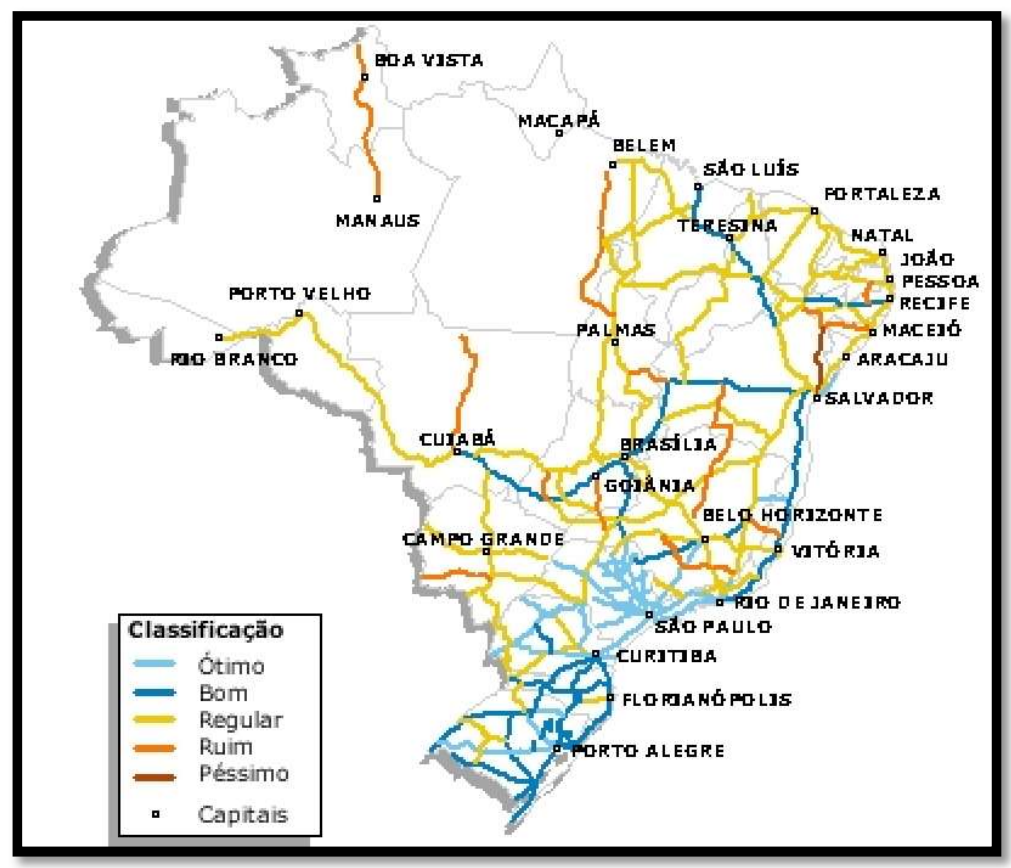

Fonte - CNT, 2007

Embora as estradas nacionais não possuam a melhor estrutura possível, e sendo apenas um vigésimo da malha americana, como afirma a revista Exame (2013), o modal rodoviário deve ser considerado nessa pesquisa, visto que é o mais importante na matriz de transportes nacional e possui diversas vantagens como a sua frequência e a capacidade de ser feito porta a porta.

\subsubsection{Transporte Ferroviário}

O segundo modal de transporte na matriz de transportes brasileira é o ferroviário, mesmo ocupando a segunda posição na matriz de transportes nacional, ainda é deficitário. Para Santos (2005) a malha ferroviária é ideal para o transporte de grandes cargas em longas distâncias e para países como o Brasil, continentais, são bastante adequadas. Conforme Ballou (2006) a estrada de ferro se caracteriza pelo alto custo fixo e ao custo variável relativamente baixo.

A ferrovia é caracterizada como um modal lento e isso ocorre principalmente devido ao fato de o vagão gastar $88 \%$ do seu tempo carregando e descarregando e locomovendo-se dentro do terminal, segundo Ballou (1993). Além disso, o transporte ferroviário necessita de 
outros modais para poder finalizar a sua entrega, pois como foi dito anteriormente, apenas o rodoviário é capaz de fazer a entrega porta a porta.

Mesmo sendo ideal para longas distâncias, no Brasil as distâncias entre as estações são curtas e boa parte serve apenas para o transporte de minério de ferro e grãos de soja. Segundo o Ministério dos Transportes, Portos e Aviação Civil (2014), o Brasil possui uma malha ferroviária de $28000 \mathrm{~km}$ com um total de 3340 de locomotivas, e é o maior da América Latina em termos de carga transportada.

Como é possível perceber na figura 2, existe uma baixa integração nas ferrovias do Brasil, o que faz uma carga vinda do Nordeste para o Sudeste precisar ser carregada e descarregada mais de uma vez, acarretando em um aumento de custos da distribuição da água de coco.

Figura 2. Mapa ferroviário Brasileiro

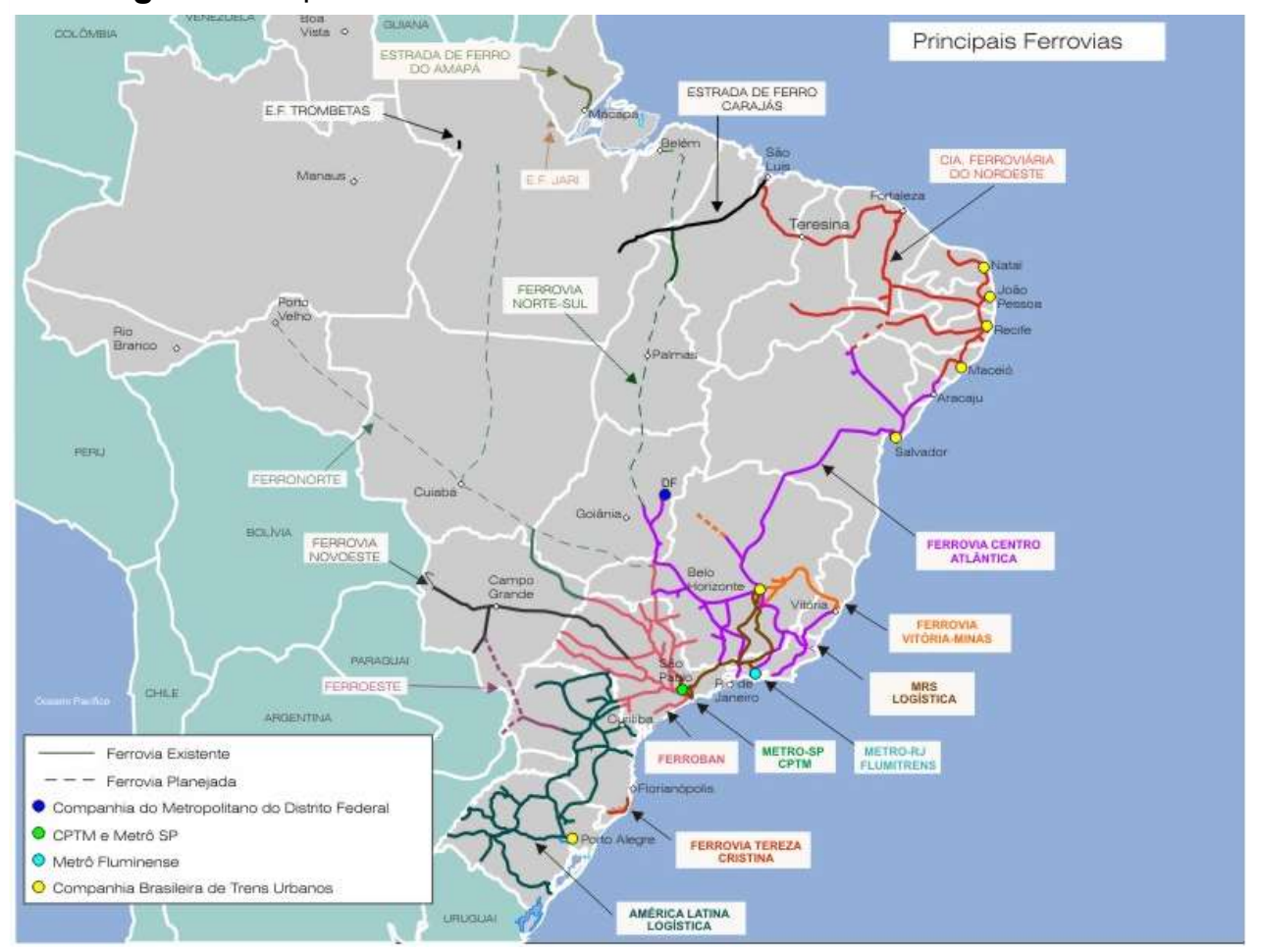

Fonte - CNT, 2011.

Devido à falta de integração da malha nacional, à exclusividade de algumas ferrovias para determinadas empresas e à pequena quantidade de água de coco que se espera trazer de Pernambuco para o Rio de Janeiro, e do produto ser perecível, devendo cumprir um prazo de validade, vê-se como impossível o frete da água de coco por meio de trens. 


\subsubsection{Transporte Hidroviário.}

Conforme Ballou (1993), o modal hidroviário possui uma pequena abrangência devido ao fato de a via ser limitada às hidrovias domésticas, o que exige a combinação com outro modal ou que o destino esteja localizado às margens do rio. Outra característica ruim, que não deve ser considerado em um país tropical como o Brasil, é o fato de no inverno os rios de países com clima frio estarem congelados. Chopra e Meindl (2003, p. 56) afirmam que o navio é o transporte mais lento, porém algumas vezes é a única opção de transporte internacional para grandes cargas. A vantagem das hidrovias em relação aos outros modais é o seu baixo custo de manutenção e de transporte, e a sua grande capacidade de carga.

Mesmo com o transporte hidroviário possuindo algumas desvantagens, o Brasil possui o $16^{\circ}$ maior litoral do mundo, com uma extensão de 8,5 mil quilômetros de costa navegáveis, além de uma rede hidroviária de $37800 \mathrm{~km}$, segundo a ANTAQ (2006), sendo as Bacias Amazônica, do São Francisco e do Paraguai as três mais importantes, respectivamente. O País possui trinta e quatro portos públicos, incluindo seis no Estado do Rio de Janeiro e um no Estado de Pernambuco. 
Figura 3. Principais Hidrovias do Brasil

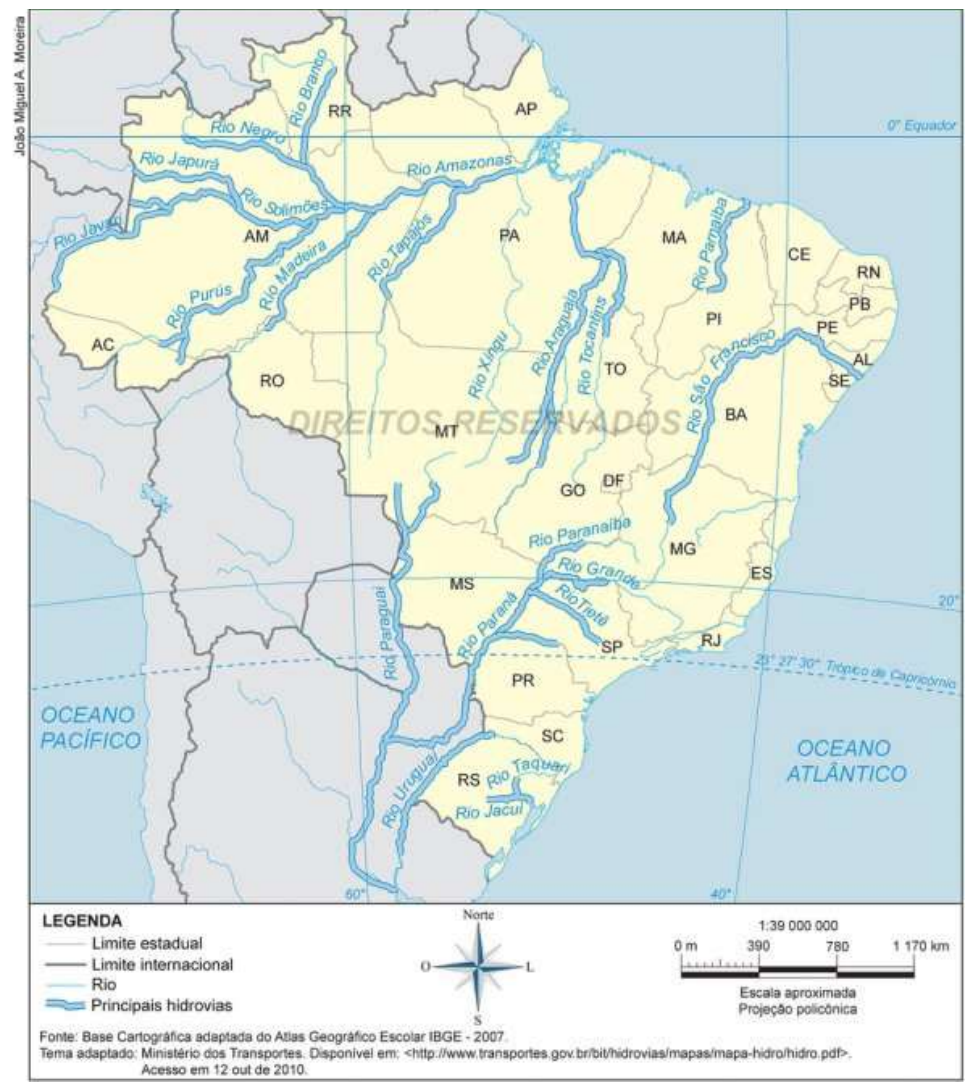

Fonte - Base Cartográfica adaptada do Atlas Geográfico Escolar IBGE, 2007.

Como podemos perceber com a figura 3, seria impossível transportar diretamente por meio de rios entre o Estado de Pernambuco e do Rio de Janeiro a carga, sem a interferência de outro modal. Porém como os dois estados são litorâneos e possuem portos no cenário brasileiro, faz-se da cabotagem como alternativa para o transporte desta carga.

\subsubsection{Transporte por dutos}

O transporte por meio de dutos é principalmente utilizado na movimentação de óleo e gás. "O modal dutoviário é considerado o mais consistente e frequente de todos os modais. Isso ocorre porque a variância no tempo de transporte é mínima (maior consistência) e as dutovias funcionam 24 horas por dia (frequência). Por outro lado, é o modal que apresenta menor velocidade, menor capacidade (uma vez que é muito especializado, transporta pequena variedade de produtos) e menor disponibilidade, afinal, está presente em poucas regiões." (Vaz, 2005, p.1). 
Figura 4. Mapa dutoviário brasileiro

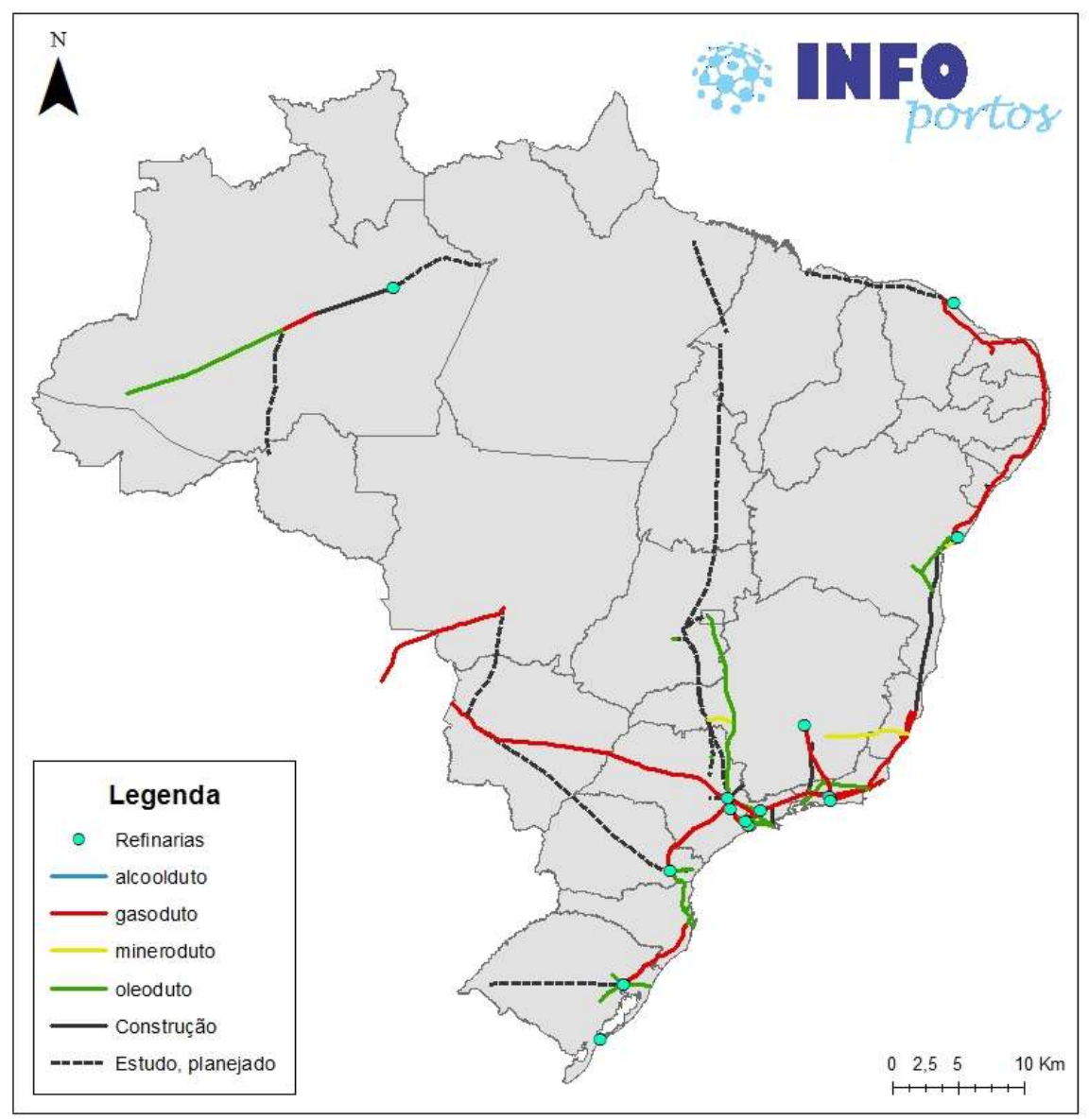

Fonte: ANP, 2015

Como é possível perceber na figura 4, o sistema dutoviário brasileiro ainda não está $100 \%$ integrado, com a ligação Nordeste-Sudeste ainda em construção. Além do fato de não possuir tecnologia ainda para o transporte de sólidos. Assim, torna-se impossível um estudo mais aprofundado do transporte da água de coco por dutos.

\subsubsection{Transporte aeroviário.}

Embora possua um valor de frete três vezes maior do que o transporte rodoviário e quatorze vezes superior ao ferroviário, o transporte aéreo possui algumas peculiaridades em relação aos outros meios da matriz de transporte. Tal qual a Apostila de sistemas de Transportes da UFPR (2013), o frete por vias aéreas é o ideal para a condução de cargas com alto valor agregado e com caráter imediato.

O transporte por avião é o mais veloz em relação a todos outros meios disponíveis na matriz de transporte. Segundo Ballou (1993), o transporte aéreo é limitado devido ao pequeno tamanho dos porões do avião, porém em relação aos outros transportes, a carga precisa de 
menor proteção, desde que durante o transporte do aeroporto até o destino final, o produto não seja exposto a danos.

Segundo a Agência Nacional de Aviação Civil (2016), ANAC, o Brasil possui um total de 2463 aeródromos, sendo a segunda maior nação do mundo nesse quesito, sendo que o aeroporto de Petrolina (PE) e os dois da cidade do Rio de Janeiro estão entre os mais movimentados do Brasil. Considerando os fatores listados, o transporte de água de coco por vias aéreas será considerado para o presente estudo.

\subsubsection{Serviços Integrados (Multimodais)}

Os serviços integrados se caracterizam pelo transporte através de mais de um modal da matriz de transporte, afirma Ballou (1993). Para a integração destes modais, é recomendável a utilização do contêiner padrão que é transferível entre todos os modais, com exceção de dutos. A vantagem da utilização do contêiner padrão é que este evita a permutação custosa entre os modais, além de ser porta a porta quando combinada com o caminhão.

Após uma breve análise da matriz de transportes brasileira, verifica-se que o transporte da água de coco apenas seria viável por meio de caminhão, ou através da integração entre o modal rodoviário com o aéreo ou aquático, ou seja, através de serviços integrados. Assim, o transporte dutoviário e ferroviário são desconsiderados no estudo.

\subsection{Características técnicas da água de coco.}

Conforme a Instrução Normativa $n^{\circ} 39$, 2002, art. 87, parágrafo único, inciso II, da Constituição, tendo em vista o disposto no art. 159, incisos I, alínea "a", e II, e art. 42, do Regulamento da Lei $n^{\circ}$ 8.918, de 14 de julho de 1994 a água de coco é: "a bebida obtida da parte líquida do fruto do coqueiro (Cocus nucifera L.), por meio de processo tecnológico adequado, não diluído e não fermentado." A classificação da água de coco e suas respectivas características estão descritas na tabela 3. 
Tabela 3. Classificação e descrição de cada processo em que a água de coco pode ser comercializada.

\begin{tabular}{|c|c|}
\hline Descrição & Designação \\
\hline "In Natura" & $\begin{array}{l}\text { Produto destinado para consumo imediato e que não tenha sido submetido a } \\
\text { nenhum processo físico ou químico processo }\end{array}$ \\
\hline Esterilizada & Produto submetido a um processo adequado de esterilização comercial \\
\hline Congelada & $\begin{array}{l}\text { Produto que tenha passado por um processo de congelamento, podendo ser ou não } \\
\text { pasteurizado. }\end{array}$ \\
\hline Resfriada & Produto submetido a um processo de pasteurização e resfriamento \\
\hline Concentrada & $\begin{array}{l}\text { Processo cuja concentração de sólidos solúveis seja igual ou superior ao dobro da } \\
\qquad \text { sua concentração natural }\end{array}$ \\
\hline Desidratada & $\begin{array}{l}\text { Definido como o produto submetido a um processo adequado de desidratação, cujo } \\
\qquad \text { teor de umidade seja inferior a } 3 \% .\end{array}$ \\
\hline
\end{tabular}

Fonte: Ministério de Estado, Interino, da Agricultura, Pecuária e abastecimento, 2002.

Por esse estudo se tratar apenas da água de coco resfriada e pronta para consumo, o trabalho procurará focar maior no produto com esta característica. De acordo com a Instrução Normativa $N^{\circ} 39$ este produto deve seguir a padronização presente na tabela 4 :

Tabela 4. Composição e requisitos para a venda de água de coco.

\begin{tabular}{|c|c|}
\hline Características & Requisitos obrigatórios \\
\hline Ingrediente obrigatório & Água de coco \\
\hline Ingredientes Opcionais & $\begin{array}{l}\text { Podem ser adicionados açúcares exclusivamente para a correção e } \\
\text { padronização do produto e vitaminas conforme legislação }\end{array}$ \\
\hline Aparência & $\begin{array}{l}\text { Característica, variando de translúcido a opaco. Podendo possuir pequena } \\
\text { quantidade de partículas de polpa do coco. }\end{array}$ \\
\hline Estocagem & A água de coco resfriada deve ser vendida á temperatura máxima de $+10^{\circ}$ \\
\hline
\end{tabular}

Fonte: Ministério de Estado, Interino, da Agricultura, Pecuária e abastecimento, 2002.

\subsubsection{Engarrafamento do produto}

Segundo o fabricante do produto D'miro água de coco por contato telefônico, geralmente o produto é um mix de $40 \%$ de cocos verdes e $60 \%$ de cocos maduros que, de acordo com o cliente, pode variar. Quanto maior a proporção de coco maduro, mais doce será o produto final.

Após a seleção dos frutos, estes são encaminhados para uma esteira em que são lavados e furados um por um. Assim que o coco é furado, o líquido é despejado em uma bacia. 
Após a bacia ficar cheia, os copinhos são engarrafados. É de extrema importância mencionar que a partir do momento que o líquido está na bacia, o produto permanece abaixo dos $5^{\circ} \mathrm{C}$ até o consumo do cliente, para assim não haver alteração no sabor. De acordo com o fabricante a água de coco oxida acima da temperatura de $5^{\circ}$, diminuindo a sua validade.

Ainda de acordo com o fabricante, após esse processo de engarrafamento, o produto possui validade de 30 dias enquanto resfriada e de até seis meses quando abaixo de $-2^{\circ} \mathrm{C}$, temperatura que congela o produto. Para que o produto mantenha as suas características de sabor e aparência, é indicado que seja descongelado dentro da geladeira, jamais com métodos alternativos, como o microondas.

\subsubsection{Embalagem}

Segundo Ballou (1993) a embalagem tem função de armazenagem e demonstração do produto, ou seja, deve avisar para o consumidor o que é o produto de maneira objetiva e criar desejo no consumidor, e do ponto de vista logístico, a embalagem deve proteger o produto e facilitar o seu manuseio. Para tal função o fabricante utiliza um copo de $300 \mathrm{ml}$ como o da figura 5 que vem em uma embalagem para proteção de papelão cuja capacidade é de 24 copos. Assim, o manuseio é facilitado e também a proteção dos copos. 
Figura 5. Modelo de copo do Fabricante

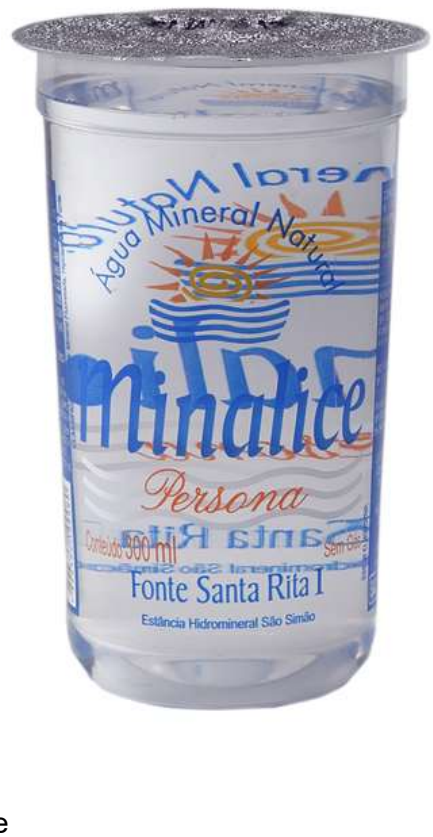

Fonte - Fabricante

Assim, como mostra a figura 5, o copo do fabricante é translúcido de maneira que o cliente veja a aparência do produto. O copo do fabricante também informa para o cliente aspectos técnicos, como a validade e o modo de armazenagem.

\subsubsection{Estocagem do produto}

Pela impossibilidade da previsão de $100 \%$ da demanda futura, é primordial para uma empresa que ela mantenha determinado volume de estoque. Ballou (1993) afirma que o estoque mantém a disponibilidade de mercadoria, além de permitir economia de escala nas compras e no transporte, fora a segurança contra contingências.

Dentro dos custos de estocagem deve ser considerado o custo de manutenção do estoque, os custos de aquisição e os custos de falta. O primeiro é relativo a tudo que envolve a manutenção em estoque da mercadoria por determinado período de tempo, desde a conta de luz até o custo de imobilização de capital. O custo de aquisição se relaciona com o valor de reposição do estoque, e por último temos o custo de falta, que ocorre quando existe uma demanda, mas não há produtos para venda: esse custo pode ser contabilizado com a imagem negativa que o cliente pode passar a olhar para a empresa, até com custo de atraso.

Como a ideia é a compra de cerca de 15000 copos, 10500 litros, a cada leva, é necessário que esta quantidade seja possível para armazenagem, e como foi visto nas 
características técnicas do produto, estes devem ser armazenados em temperaturas abaixo dos $5^{\circ} \mathrm{C}$ de acordo com o fabricante e $10^{\circ} \mathrm{C}$ conforme a Instrução Normativa $\mathrm{n}^{\circ} 39,2002$, acarretando na necessidade de uma câmara fria ou de refrigeradores. Como forma de exemplificação serão utilizados seis refrigeradores industriais da Iceccozinhas com capacidade de 1820 litros e dimensões de 2100×750×2050 mm, totalizando 10920 litros de capacidade de armazenamento. Este refrigerador foi escolhido devido ao fato de ele ser um dos maiores do mercado em capacidade de armazenamento e pelo fato de ele ser programável, podendo-se assim manter uma temperatura interna de $5^{\circ} \mathrm{C}$. 


\section{Métodos e procedimentos de coleta e de análise de dados do estudo.}

Este capítulo demonstra informações de como é feita a pesquisa com as empresas de transporte. O objetivo é fazer uma entrevista qualitativa com as principais empresas de frete do país que estejam regularizadas e cadastradas nos seus devidos órgãos reguladores.

\subsection{Método de pesquisa utilizado.}

Após contato com o fabricante do produto, análise das características técnicas do mesmo, e a capacidade de armazenamento do produto, o autor percebeu alguns fatores que devem ser questionados no momento de decisão de qual modal ser adotado. É importante ressaltar que o frete será de 15000 copos de 300 ml distribuídos em 625 caixas com cerca de $7.8 \mathrm{~kg}$ cada caixa com 24 copos.

Conforme o modo de avaliação proposto por Vergara (2010), em relação aos fins e quanto aos meios, tem-se:

- Quanto aos fins - Trata-se de uma investigação explicativa, pois tem como objetivo justificar confirmar o referencial teórico e, portanto esclarecê-lo.

- Quanto aos meios - Trata-se de uma pesquisa telematizada, em conjunto com uma pesquisa de campo.

Classifica-se como uma pesquisa telematizada, pois as pesquisas foram feitas por meio de telefone e computador.

Ao mesmo tempo é uma pesquisa de campo, pois o objetivo é explicar determinado fator através de questionários com empresas.

\subsection{Procedimento e coleta de dados.}

Para o desenvolvimento do estudo, o autor realizou uma pesquisa bibliográfica intensa em livros, revistas especializadas, sites e normas e procedimentos de agências reguladoras que regem a comercialização do produto.

Realizou-se uma pesquisa por telefone e e-mail utilizando uma amostra de 14 empresas grandes de frete entre todos os modais, fora as que não responderam. Visando identificar principalmente o custo do frete e o tempo, o autor elaborou um questionário semi-estruturado 
questionando exatamente essas informações e outras dúvidas que surgiam, como o tipo de transporte e algumas sugestões da empresa.

\subsection{Tratamento e análise dos dados coletados.}

Os dados foram analisados de maneira qualitativa principalmente:

Qualitativo devido ao fato de além do preço e tempo de transporte, outros fatores serem considerados para a decisão, como o atendimento e alguns outros fatores "abstratos", além disso não foi utilizado nenhum tipo de cálculo estatístico para a avaliação dos dados.

\subsection{Limitações do método.}

O autor considera como limitação do método a quantidade de empresas prestadoras de serviços de transporte pesquisado, que poderia ser maior, mas justifica-a como consequência do número limitado de empresas de frete que façam a rota entre o Estado de Pernambuco e o Rio de Janeiro. Chega-se, assim, ao final com uma amostra relativamente pequena à que considera ideal. 


\section{Apresentação e análise dos resultados}

Este capítulo, organizado em duas seções apresenta e discute os principais resultados alcançados, analisa e discute suas implicações e produz sugestões sobre o estudo previamente selecionado.

Nesta seção as empresas entrevistadas serão apresentadas, assim como as respostas respectivas de cada empresa. No final do capítulo o resultado será apresentado e discutido.

\subsection{Caracterização das empresas estudadas}

Foram pesquisadas 14 possibilidades de transportes aéreo, rodoviário e aquaviário. Todas as empresas fazem o transporte porta a porta, ou seja, excluindo a de transporte rodoviário, todas são multimodais. Por questão de organização, os tópicos estão divididos por modal, considerando o transporte de uma carga de 4875 quilos (625 caixas com 24 unidades, cada) e também com a possibilidade da carga mínima que a empresa vende que é de 200 caixas.

\subsubsection{Transporte por cabotagem}

\subsubsection{Aliança}

A primeira empresa que foi feito o contato transporta praticamente todos os tipos de produtos, desde frutas até cargas perigosas. A transportadora possui contêineres para carga seca, contêineres refrigerados e contêineres especiais para o transporte de cargas que possuam tamanho superior ao padrão de um contêiner tradicional. Para fazer o transporte de cabotagem são utilizados 10 navios de contêineres.

Em contato com a empresa, esta mencionou a possibilidade do contêiner ser rateado com outras cargas, porém ao ser questionada sobre o serviço, afirmou que o serviço está disponível apenas no Porto de Santos, o que inviabilizaria o serviço. O valor do frete total com seguro porta x porta foi de $\mathrm{R} \$ 15.000$ em um contêiner de 20' refrigerado com tempo de chegada estimado de nove dias. $\mathrm{O}$ valor desmembrado está na tabela abaixo. 
Tabela 5. Preço desmembrado Aliança

\begin{tabular}{|c|c|}
\hline Serviço & Requisitos obrigatórios \\
\hline \multirow[t]{2}{*}{ Frete aéreo Total } & $\mathrm{R} \$ 12.400,00(\mathrm{R} \$$ \\
\hline & 2,4/quilo) \\
\hline Seguro & $\begin{array}{c}\mathrm{R} \$ 150,00 \text { (por conta } \\
\text { do cliente) }\end{array}$ \\
\hline Entrega no Rio & $\mathrm{R} \$ 2.400$ \\
\hline Total de Frete & $\mathrm{R} \$ 14.950,00$ \\
\hline
\end{tabular}

\subsubsection{Costa Brasil}

A empresa Costa Brasil atende em todo o litoral brasileiro e possui uma frequência semanal de navios saindo de Pernambuco para o Rio de Janeiro. Após descobrir a viabilidade do rateio de contêiner, foi perguntado à empresa se a mesma possuía o serviço, que respondeu de maneira positiva, porém apenas para o Porto de Santos no Estado de São Paulo e de Itajaí-SC, porém em breve este serviço estará disponível no Porto de Suape-Rj, um ponto positivo para uma futura parceria com esta empresa. Diferentemente da empresa Aliança, a Costa Brasil possui pouca disponibilidade de contêiner 20' refrigerado. Assim, encaminhou também o preço para o contêiner 40'.

O serviço porta a porta desta empresa com ova e desova ficou em $R \$ 13.400$ em um contêiner de 20', e para o contêiner de 40' o custo do frete é de $R \$ 15.950$.

\subsubsection{MERCOSUL Line}

Faz parte do grupo Maersk, que possui 108000 funcionários espalhados por 130 países e líder no setor de transporte de contêineres mundial, infelizmente a empresa não respondeu o questionário a tempo, sendo assim desconsiderada para o trabalho.

\subsubsection{Login Logística Intermodal}

Possuindo sete navios e com outros três em construção, a empresa trabalha em todos estados da Região Sul do Brasil, além do Rio de Janeiro, Espírito Santo, Bahia, Ceará, 
Pernambuco, Pará e Amazonas. Infelizmente a empresa não respondeu até o horário de fechamento da pesquisa, inviabilizando a continuação de seu estudo.

\subsubsection{Transporte Aéreo}

\subsubsection{Kodex Express}

Mesmo afirmando em seu site que: "Não importa qual é o seu produto ou o seu mercado, nós temos a experiência para contribuir com o sucesso de seu negócio", a empresa afirmou que não trabalha com o transporte de produtos perecíveis, o que inviabiliza a continuação do estudo com ela.

\subsubsection{CCA Express}

Com 17 anos de experiência no mercado de logística, a CCA Express foi fundada em Caxias do Sul, RS e atualmente possui quatro filiais e 300 veículos, além de atender em 60 aeroportos espalhados por todo o Brasil. O valor total do Frete para os quase 5000 quilos de mercadoria é de $\mathrm{R} \$ 16.163,20$, com prazo de entrega de três dias.

\subsubsection{AeroExpress}

A AeroExpress é uma empresa localizada em Natal, Rio Grande do Norte especializada em frete com origem em cidades nordestinas. Além dos serviços de frete a empresa também presta serviços de passeio, translado e viagens corporativas.

De acordo com a empresa, a carga chegaria ao Rio de Janeiro em até um dia após o contrato do serviço, que ficou fechado em 10.151 reais. O custo está desmembrado na tabela 6.

Tabela 6. Preço desmembrado AeroExpress

\begin{tabular}{lc}
\hline Serviço & Requisitos obrigatórios \\
\hline Frete aéreo Total & $\mathrm{R} \$ 8.775,00(\mathrm{R} \$$ \\
& $1,8 /$ quilo $)$ \\
Seguro & $\mathrm{R} \$ 76,00$ \\
Entrega no Rio & $\mathrm{R} \$ 1.300$ \\
Total de Frete & $\mathrm{R} \$ 10.151,00$ \\
\hline Fonte - AeroExpress &
\end{tabular}


A empresa possibilita o cliente de pegar a mercadoria no aeroporto, ou seja, é possível pagar um total de $\mathrm{R} \$ 8.851,00$ caso a empresa possua algum método de coleta disponível.

\subsubsection{FlextimeCourier}

Localizada em São Paulo, SP, esta empresa trabalha tanto com o frete aéreo quanto com o rodoviário e possui capacidade de entregar em qualquer localização do país. Porém o atendente da empresa afirmou que não seria possível fazer a entrega devido ao peso da carga.

\subsubsection{Transporte rodoviário.}

\subsubsection{FlextimeCourier}

A empresa informou que devido ao tamanho da encomenda e por não trabalharem com frete refrigerado eles não poderiam fazer a entrega.

\subsubsection{Jamef}

Especializada em carga fracionada com alto valor agregado, a empresa está presente no mercado desde 1943. Segundo a empresa, a entrega entre as duas cidades pesquisadas demoraria cerca de sete dias. Porém a empresa não trabalha com frete refrigerado.

\subsubsection{Custódia transportes}

A empresa trabalha com frete refrigerado apenas na Região Sudeste, indicando que não se poderia contar com ela para o presente estudo.

\subsubsection{MG Frete}

A empresa afirmou que está evitando algumas regiões do Estado devido à quantidade de assaltos, porém conseguiria trazer com frete de retorno, cobrando $\mathrm{R} \$ 5.500$ de custo total, pois seria compartilhado com outra empresa, visto que seria utilizado um caminhão com capacidade de sete toneladas. Depois de carregado o caminhão, a carga chegaria em três dias. Com a utilização do transporte dedicado, isto é, sem uso de carga de retorno, o custo total ficou em $\mathrm{R} \$ 10.500$. 


\subsubsection{Arcelog}

Não faz transporte da carga entre os dois destinos, dedicando-se apenas ao mercado do Mercosul.

\subsubsection{Frete de retorno.}

Segundo o fabricante da empresa de água de coco "Aja coco", empresa com produção em Petrolina de água de coco pasteurizada, existe um local na cidade em que caminhoneiros esperam para receberem propostas com frete de retorno. Isso acontece porque, como mencionado na seção 2.2.1, não existe tanta demanda de produtos do Nordeste para o Sul e Sudeste. Assim, é possível conseguir o transporte por $\mathrm{R} \$ 3.500$. Segundo o mesmo fabricante geralmente esses transportes são próprios de empresas grandes como a Sadia, e não de terceiros. Assim, algumas vezes não existe a possibilidade deste tipo de serviço estar disponível, com o cliente necessitando de um pouco de sorte.

\subsection{Análise dos resultados}

Aparentemente o mercado de fretes brasileiro não é totalmente desenvolvido e é ineficiente, sendo dominado por poucas empresas que abocanham grande parte do mercado. Além disso, as empresas rodoviárias consideram a região estudada perigosa, fora que na maioria das vezes não possuem capacidade para transporte frigorificado.

As empresas aéreas, como citado na monografia, são mais velozes em relação aos outros modais e são ideiais em contexto de urgência, porém isso tem um preço, e para grandes quantidades não parece compensar a utilização deste modal.

As empresas de cabotagem indicam que o peso total do conteúdo não influencia no preço final do frete (limitando-se a $25.400 \mathrm{Kg}$ para o contêiner refrigerado com 20', de acordo com a empresa Impacto - Logística internacional). Logo, este modal é aconselhado para o transporte de grandes quantidades, visto que gera economia de escala.

A pesquisa com as empresas confirmou o que o referencial bibliográfico apresenta e para corroborar com a pesquisa foi elaborado um gráfico demonstrando o ponto em que cada quantidade é mais barato e qual modal escolher.

Como o gráfico abaixo aponta, o frete por cabotagem realmente é o mais barato em transportes de grandes quantidades, e o rodoviário para quantidades médias. Porém, algo que foi percebido na pesquisa e um tanto surpreendente, é que para a quantidade mínima que o produtor vende $1560 \mathrm{~kg}$ ou 200 caixas, o transporte mais barato é o aéreo, como pode ser percebido no gráfico da figura 6. 
Figura 6. Preço unitário/quantidade em cada modal

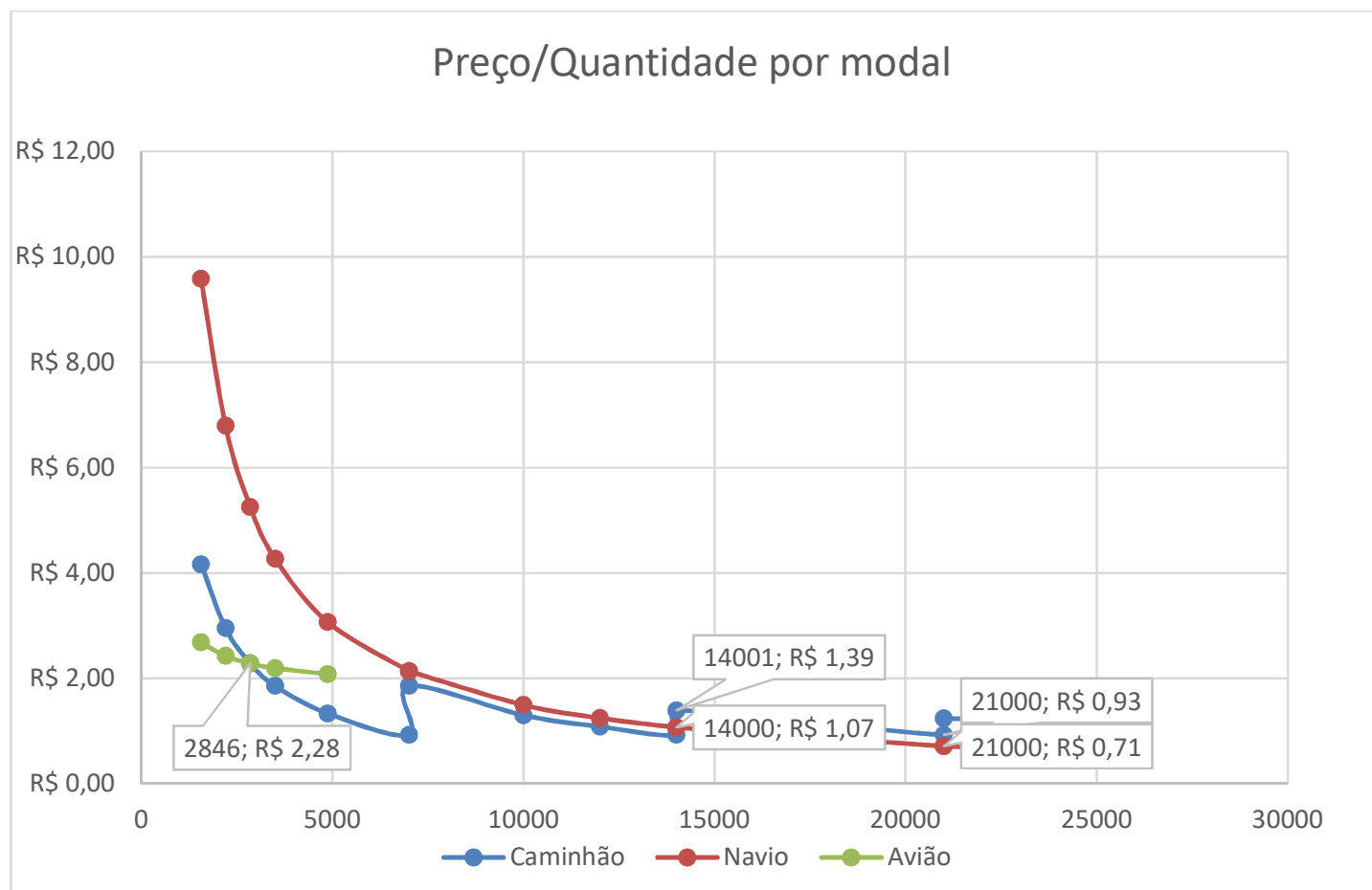

Fonte $-\mathrm{O}$ autor.

O gráfico foi elaborado da seguinte maneira:

- Em todos os modais foi considerado o preço da entrega porta x porta

- Foi considerado o valor do frete da empresa Aliança que possui maior disponibilidade no contêiner de 20' no navio.

- A função do Preço da cabotagem é: Preço unitário = 14950/quantidade.

- Foi considerado o melhor orçamento no transporte de avião, sendo a sua função feita da seguinte maneira: Preço $=1.8 x+1376$. $X>200$. O valor de 1,8 é o preço do quilo negociado com a empresa Aero-Express. Por não ter cotado valores acima de 4875 quilos, a partir desse montante o avião não é mais considerado.

- Visto que existe a possibilidade de não haver frete de retorno nem fracionado entre os destinos, foi calculado a média das três possibilidades gerando um resultado de $\mathrm{R} \$ 6500,00$.

- A prova real com os pontos se encontra no Anexo A, no final do trabalho. 
A utilização do transporte aéreo é o mais barato para uma quantidade de até $2846 \mathrm{~kg}$ de produto. Logo, nestas condições, este seria o modal utilizado, visto que é também o mais rápido e eficiente. Depois deste ponto o caminhão se torna o transporte mais barato, a cabotagem é o transporte de melhor preço a partir da necessidade de um terceiro caminhão, ou seja, a partir dos $14001 \mathrm{~kg}$, ou 43080 copos. 


\section{Conclusões e recomendações para novos estudos.}

Apesar de poucas serem as empresas que trabalham com a rota Petrolina-PE $x$ Rio de Janeiro-RJ e dos problemas em relação a estradas e segurança na região, o que dificulta uma pesquisa de preços mais aprofundada e com maior quantidade de informações, a pesquisa demonstrou a viabilidade logística no transporte do produto, visto que nenhum dos modais demora mais de nove dias para realizar o frete na rota analisada. Este tempo permite, ainda, a possibilidade de se escoar essa carga para consumo no destino final - Rio de Janeiro-RJ, por mais 21 dias.

Os modais estudados refletiram o que se pesquisou em termos de bibliografia, visto que os modais rodoviário e aquaviário são os mais indicados para médias e grandes cargas respectivamente, e em relação ao tempo de transporte a bibliografia também foi confirmada.

Um dos aspectos mais surpreendentes para o autor foi o fato de que, apesar de os estudos tradicionais sobre a seleção de modais de transporte, o modal aéreo, geralmente recomendado para produtos de maior valor agregado, é perfeitamente viável no produto estudado e é inclusive o recomendado para quantidades menores e dentro do limite mínimo de fornecimento do produtor localizado em Petrolina-PE no trecho considerado.

\subsection{Sugestões e recomendações para novos estudos}

Como existe uma grande dificuldade de se encontrar empresas que trabalhem com a rota Petrolina - Rio de Janeiro, poderia ser considerado em um novo estudo a rota Salvador/BA - Rio de Janeiro, visto que esta cidade é a maior exportadora do Nordeste segundo a PRODETEC. Esse estudo, provavelmente, seria mais rico em detalhes e informações.

Outra possibilidade de estudo seria uma pesquisa aprofundada em embalagens e métodos de armazenamento para o produto estudado neste trabalho e outros com características semelhantes. A realização de uma pesquisa sobre produtos agrícolas como frutas e legumes poderia ser de grande valor, visto que Petrolina é uma cidade com produção agrícola intensa e com produtos agrícolas utilizados na Região Sudeste.

Como o principal objetivo deste trabalho foi descobrir o método mais barato de transporte, estudar a abertura de uma fábrica de água de coco engarrafada no Rio de Janeiro 
ou cidades próximas poderia concluir que isto seria mais vantajoso do que o pagamento de um frete constantemente. 


\section{Referências Bibliográficas}

Aeroexpress, obtido via internet: www.aeroexpress.com.br, acesso em novembro de 2016.

Agência Prodetec "Nordeste concentra exportação em poucos Estados e empresas". Made in Nordeste, Julho de 2014. Disponível em < http://www.agenciaprodetec.com.br/madeinnordeste/649-nordeste-concentra-exportacaoem-poucos-estados-e-empresas-.html>.

Aliança, obtido via internet: www.aliança.com.br, acesso em novembro de 2016.

Arcelog, obtido via internet: www.arcelog.com.br, acesso em novembro de 2016.

Associação Nacional de Transporte Aquaviário - ANTAQ. Transporte Aquaviário no Brasil. Brasília: 2006.

BALLOU, Ronald H. Gerenciamento da Cadeia de Suprimentos/ Logística Empresarial. 5. Ed. Bookman, 2006.

BALLOU, Ronald H. Logística empresarial: Transportes, administração de materiais e distribuição Física. 1. Ed. Atlas, 1993.

CCA Express, obtido via internet: www.ccaexpress.com.br, acesso em acesso em novembro de 2016.

CHOPRA, Sunil; MEINDL, Peter. Gerenciamento da cadeia de suprimentos: Estratégia, Planejamento e Operação. 1.Ed. São Paulo: Prentice Hall, 2003.

COMEX do Brasil, Sudeste lidera o ranking dos exportadores por região com US\$ 37,609 bilhões exportados, obtido via internet: http://www.comexdobrasil.com/sudestelidera-ranking-dos-exportadores-por-regiao-com-us-37609-bilhoes-exportados/, acesso em outubro de 2016.

Confederação Nacional do transporte - CNT. Pesquisa CNT de Rodovias: relatório gerencial. - 20.ed. Brasília: 2016

Costa Brasil, contato obtido via internet: www.cbcabotagem.com.br, acesso em novembro de 2016.

Exame. "A malha de estradas brasileiras é um vigésimo da americana”. São Paulo, junho de 2013, Disponível em <http://exame.abril.com.br/revista-exame/por-que-no-brasiltodo-nao-e-assim/>

FLEURY, Paulo Fernando et al. Logística Empresarial: A perspectiva Brasileira. 1. ed. São Paulo: Atlas, 2000. 

de 2016

FlextimeCourier, obtido via internet: www.flextimecourier.com.br, acesso em novembro

FONTENELE, Raimundo Eduardo Silveira. Cultura do coco no Brasil: caracterização do mercado atual e perspectivas futuras. In: CONGRESSO DA SOBER. 2005. P. 20-23.

Globo.com. "A 15 dias do verão, preços sobem na praia e cariocas resistem ao consumo". Rio de Janeiro, dezembro de 2014. Disponível em <http://g1.globo.com/rio-dejaneiro/noticia/2014/12/15-dias-do-verao-precos-sobem-na-praia-e-cariocas-resistem-aoconsumo.html >

Jamef Encomendas Urgentes, obtido via internet: www.jamef.com.br, acesso em novembro de 2016.

KOTLER, Philip; KELLER, Kevin. Administração de marketing. 12. ed. São Paulo: Pearson Prentice Hall, 2006.

Kodex, obtido via internet: kodexexpress.com, acesso em novembro de 2016.

Log-in Logística Intermodal, obtido via internet: www.loginlogistica.com.br, acesso em novembro de 2016.

MARTINS, C. R. et al. Evolução da produção de coco no Brasil e o comércio internacional: panorama 2010. Embrapa Tabuleiros Costeiros. Documentos, 2011. 2016.

Mercosul-Line, obtido via internet: www.mercosul-line.com.br, acesso em novembro de

Ministério dos Transportes, Portos e Aviação Civil, Transporte Ferroviário, obtido via internet: http://www.transportes.gov.br/transporte-ferroviario.html, acesso em novembro de 2016.

NOEL, FRANCISCO LUIZ. Verão movido à água de coco. Problemas Brasileiros, v. 46, n. 386, 2008.

Revista Globo Rural. "O maior coqueiral do mundo". Empreenda Rio de Janeiro, maio de 2015. Disponível em <http://revistagloborural.globo.com/Revista/Common/0, EMI33729818283,00-O+MAIOR+COQUEIRAL+DO+MUNDO.html>.

SANTOS, Silvio. Um estudo sobre a participação do modal ferroviário no transporte de cardas no Brasil. 159 f. Dissertação (Mestrado) - Departamento de Engenharia Civil, Universidade Federal de Santa Catarina - UFSC, 2005.

Secretaria de Aviação Civil. Aeroportos. Obtido via internet: http://www.aviacao.gov.br/assuntos/aeroportos, acesso em novembro de 2016.

SOLOMON, Michael R. O comportamento do consumidor: comprando, possuindo e sendo. 5. ed. Porto Alegre: Bookman, 2002.

VAZ, Alexildo Velozo et al. O Modal Dutoviário: Análise da importância e considerações sobre suas principais características: Programa de Mestrado em Engenharia de Transportes - PETRAN. Universidade Federal do Ceará, 2005.

Vergara, Sylvia C.- Projetos e Relatórios de Pesquisa em Administração, São Paulo Atlas, 2010 


\section{Apêndice}

Apêndice $A$

Prova real da figura 6. Estes são os pontos do gráfico.

Tabela I

\begin{tabular}{|c|c|c|c|}
\multicolumn{1}{c}{$\mathrm{F}(\mathrm{x})=$} & Preço/Quantidade & Preço/Quantidade & \multicolumn{1}{c|}{$(1376+(1,8$ * preço $)) /$ preço } \\
\hline Quantidade & Caminhão & Navio & Avião \\
\hline 1560 & $\mathrm{R} \$ 4,17$ & $\mathrm{R} \$ 9,58$ & $\mathrm{R} \$ 2,68$ \\
\hline 2200 & $\mathrm{R} \$ 2,95$ & $\mathrm{R} \$ 6,80$ & $\mathrm{R} \$ 2,43$ \\
\hline 2846 & $\mathrm{R} \$ 2,28$ & $\mathrm{R} \$ 5,25$ & $\mathrm{R} \$ 2,28$ \\
\hline 3500 & $\mathrm{R} \$ 1,86$ & $\mathrm{R} \$ 4,27$ & $\mathrm{R} \$ 2,19$ \\
\hline 4875 & $\mathrm{R} \$ 1,33$ & $\mathrm{R} \$ 3,07$ & $\mathrm{R} \$ 2,08$ \\
\hline 7000 & $\mathrm{R} \$ 0,93$ & $\mathrm{R} \$ 2,14$ & \\
\hline 7001 & $\mathrm{R} \$ 1,86$ & $\mathrm{R} \$ 2,14$ & \\
\hline 10000 & $\mathrm{R} \$ 1,30$ & $\mathrm{R} \$ 1,50$ & \\
\hline 12000 & $\mathrm{R} \$ 1,08$ & $\mathrm{R} \$ 1,25$ & \\
\hline 14000 & $\mathrm{R} \$ 0,93$ & $\mathrm{R} \$ 1,07$ & \\
\hline 14001 & $\mathrm{R} \$ 1,39$ & $\mathrm{R} \$ 1,07$ & \\
\hline 21000 & $\mathrm{R} \$ 0,93$ & $\mathrm{R} \$ 0,71$ & \\
\hline 21001 & $\mathrm{R} \$ 1,24$ & $\mathrm{R} \$ 0,71$ & \\
\hline 25400 & $\mathrm{R} \$ 1,02$ & $\mathrm{R} \$ 0,59$ & \\
\hline
\end{tabular}

Apêndice $B$

O questionário foi feito com as seguintes perguntas:

Qual o valor do frete?

Qual é tempo de entrega?

É possível compartilhar a entrega? 